\title{
Aus der Nähe III: Alja Kudrjaševa
}

Alja Kudrjaševa eröffnet ihren Blog 〈izubr〉 am 4. Juni 2003 mit einem Gedicht, nachdem ihr eine Freundin den ŽŽZZZugang eingerichtet hat (Obydenkin 2008). Die Autorin verzichtet darauf, sich selbst vorzustellen oder die Konzeption ihres Blogs zu skizzieren, sondern lässt ihren Text ohne jegliche Rahmung und fast unkommentiert für sich sprechen; nicht einmal ein Titel ist angegeben, lediglich das Entstehungsdatum des Gedichts, der 6. Dezember 2002, wird angeführt. Die literarische Ausrichtung ist dieser Online-persona damit gleichsam in die Wiege gelegt:

Наверное, это такой заколдованный круг,

Который уйдет не со мной, а немножечко позже,

Сплетен он из наших привычек, гостиных и рук

И накрепко скован обещанной наскоро ложью...

Минуты, что были потеряны годы назад

Вернутся ко мне, но в другом полукружии стрелок;

И снова смотрю я в забытые чьи-то глаза

И помню, что видел... Когда?.. Да, она тогда пела,

И голос её завораживал... Кончился миг,

И маятник, поколебавшись, качнулся обратно,

И памяти нет. Есть реальность. Я снова старик,

И только слезами размытые светлые пятна

На желтом листке. Это было, конечно, письмо, Да, если на свет посмотреть, проступают чернила... 
На старых воротах тяжелый висячий замок...

Она меня раньше... наверное... даже... любила?..

$6.12 .02^{1}$

(Kudrjaševa 2003a)

Dieser Text ist aufgrund seiner Gliederung sofort als Gedicht erkennbar, das aus vier Strophen zu jeweils vier Verszeilen besteht. Das Metrum ist ein regelmäßiger fünfhebiger Amphibrachus. Laut Michail Gasparov (2000: 196) sind dreisilbige Metren besonders in der Lyrik des russischen Realismus in der zweiten Hälfte des 19. Jahrhunderts populär; sie bieten allerdings wenig Raum für rhythmische Experimente (ebd.: 241). Üblich sind, wie Barry P. Scherr (1986: 99) Scheer ausführt, drei-, mit Einschränkungen auch zwei- und vierhebige Metren. Hier setzt sich Kudrjaševa mit ihren fünfhebigen Versen von der Tradition ab.

Der Reim bricht ebenfalls ein Stück weit aus einer strengen Regelmäßigkeit aus: Der Kreuzreim umfasst sowohl einen unreinen Reim назад - глаза als auch zwei Waisen, also zwei Verse, die sich nicht reimen: стрелок - пела und письмо - замок. Kudrjaševas Online-Debut ist also mehrfach ungewöhnlich; zunächst verweist sie über den Anapäst auf die realistische Lyrik, die, so Gasparov, zum ersten Mal in der russischen Literaturgeschichte in der Bedeutung hinter die Prosa zurücktrete (Gasparov 2000: 168). Indem Kudrjaševa die Verse über das übliche Maß hinaus verlängert, unterwandert sie die lyrische Tradition des Realismus gleichzeitig wieder.

Auffällig ist, dass das Gedicht den Blog-Kontext, in den es gestellt wird, nicht aufruft. Weder experimentiert es mit Hypertext-Elementen, noch wird Internet-Kommunikation in den Mittelpunkt gerückt. Ganz im Gegenteil ist es ein vergilbter Brief, der als Verbindung in die Vergangenheit fungiert: »И только слезами размытые светлые пятна / На желтом листке.« [»Und nur helle Flecken von vergossenen

$\mathbf{1} \mid »$ Wahrscheinlich ist das so ein verzauberter Kreis, / Der nicht mit mir verschwindet, sondern ein ganz klein wenig später, / Geflochten ist er aus unseren Gewohnheiten, Gästen und Händen / Und stark geschmiedet mit schnell versprochener Lüge ... // Minuten, die Jahre zuvor verloren wurden / Kommen zu mir zurück, aber in den anderen Halbkreis des Zifferblatts; / Und erneut schaue ich in längst vergessene Augen / Und erinnere mich, was ich gesehen habe ... Wann? .. Ja, sie sang damals, // Und ihre Stimme umfasste sie ... Der Augenblick endete, / Und das Pendel sprang schwankend zurück, / Und es gibt keine Erinnerung. Es gibt die Realität. Ich bin erneut ein alter Mann, / Und nur helle Flecken von vergossenen Tränen / bleiben auf dem vergilbten Blatt. Es war, natürlich, ein Brief, / Ja, wenn man auf die Welt schaut, kommt die Tinte .../ An alten Toren ein schweres Vorhangschloss ... / Sie hat mich früher ... wahrscheinlich ... sogar ... geliebt? .. / 6.12.02« 
Tränen / bleiben auf dem vergilbten Blatt«]. Auch formal spielt das Gedicht nicht auf den Blog an, wie die zwei sichtbaren Datumsangaben verdeutlichen. Das Gedicht wurde vorgeblich am 6. Dezember 2002 geschrieben und am 4. Juni 2003 im ŽŽ veröffentlicht - die Sichtbarmachung dieses zeitlichen Unterschiedes unterläuft die gefühlte Unmittelbarkeit der Internetkommunikation (vgl. Seite 37). In diesem konkreten Fall wird der Blog auf die Rolle der kostenlosen Publikationsplattform reduziert. Einzige Ausnahme ist die Kommentarfunktion, die in traditionellen literarischen (Träger-)Medien in der Form nicht existiert; mit gerade einmal vier Kommentaren wird diese allerdings kaum genutzt.

Kudrjaševa gibt in diesem Gedicht keine Richtung für die imaginierte Performativität aufseiten des Publikums vor. Eine explizite (Selbst-)Inszenierung findet nicht statt. Wie wenig Imaginationspfade die Autorin hinsichtlich ihrer Autor-persona vorgibt, zeigt sich daran, dass das lyrische Subjekt des oben zitierten Gedichts männlich ist. Eine Verwechslung mit einem (auto-)biographischen $>$ Ich $\prec$, die natürlich problematisch wäre, ist damit unmöglich. Selbst bei einem zwei Monate später veröffentlichten Gedicht setzt Kudrjaševa auf diese Sichtbarmachung des lyrischen Subjekts in der Differenz: Wieder spricht ein >er<: »Я совсем наверно спятил - / Можно было ведь остаться ... « [»Ich bin wahrscheinlich vollkommen übergeschnappt - / Man hätte ja bleiben können ...«], obwohl das Gedicht vorgeblich Kudrjaševas Eindrücke einer Reise wiedergibt: »По впечатлениям вчерашней поездки в Мурманск« [»Inspiriert durch die gestrige Fahrt nach Murmansk «] (Kudrjaševa 2003b).

Diese Distanz ist wohl eine bewusste Entscheidung und als solche Teil einer Strategie der (Selbst-)Inszenierung, die nicht auf konkrete Autorinnen- bzw. Autorenbilder abzielt, sondern diese unterbindet. Kudrjaševa versucht, ihre Gedichte nach Möglichkeit von ihrer Person abzukoppeln. Damit funktionieren diese Texte aber nicht als Ventil für ihre Persönlichkeit. Als Ausweg eröffnet die Autorin 2005 einen zweiten Blog: 〈xelbot〉. Nach der Beziehung zwischen〈izubr〉 und 〈xelbot〉 gefragt, spricht Kudrjaševa von einer »раздвоение личности « [»Persönlichkeitsspaltung «] und bezeichnet den neuen Blog als »свое второе >я «« [»mein zweites $>$ Ich $\ll$ « $(\mathrm{Ku}-$ drjaševa 2005g).

Drei Jahre später sieht sie die beiden Blogs nicht mehr als zwei Aspekte ihrer Persönlichkeit, der lyrische 〈izubr〉 wird vielmehr zu einem Anderen: »А вообще я стараюсь, чтобы люди, которые общаются со мной, общались бы именно со мной, а не с ЖЖ-юзером izubr. « [»Überhaupt liegt mir daran, dass die Menschen, die sich mit mir unterhalten, tatsächlich mit mir sprechen und nicht mit dem ŽZ̆User izubr. «] (Obydenkin 2008). Mit dieser Aussage betont sie nicht nur die Spaltung zwischen den Blogs bzw. den beiden Online-personae, sondern markiert 〈izubr〉 als etwas ihr Fremdes, als Online-Persönlichkeit, mit der sie offline nichts zu tun haben 
möchte. Kudrjaševa selbst vermutet, gerade diese Trennung mache den Reiz ihrer Gedichte aus: »я очень обычный человек и пишу про очень обычные штуки. И всем нравится - будто бы про них.« [»Ich bin ein überaus gewöhnlicher Mensch und schreibe über überaus gewöhnliche Dinge. Und allen gefällt es - als ob die Gedichte von ihnen handeln würden.«] (Obydenkin 2008). Für den Fall, dass die Autorin Recht hat und sich das Publikum in ihren Texten wiederfinden will, dann funktioniert dies nur, wenn dieser Imagination keine dominante schriftstellerische Persönlichkeit im Weg steht; ein gewisser Abstand zwischen Autorin und ihren Texten ist dabei hilfreich. 2011 verneint Kudrjaševa von Neuem eine biographistische Lesart ihrer Gedichte. Ihr gewöhnliches >Ich< ließe sich dafür aus ihrem (auto-)biographischen Blog 〈xelbot〉 ablesen, sie verfolgt damit wie so viele Bloggerinnen und Blogger die Strategie der inszenierten Authentizität:

Я не считаю, что я и мои стихи - это одно и то же. Второй блог читают те, кому интересна я. Здесь я общаюсь с друзьями, не оглядываюсь на аудиторию, могу послать всех на фиг, если захочется... Зачем мне перед кем-то оправдываться за то, что я обычный человек? Нет, я этим горжусь. ${ }^{2}$ (Alechin 2011)

Einen weiteren Schritt in Richtung inszenierte Authentizität setzt Kudrjaševa auf Facebook, wo sie - wie im Übrigen auch auf Vkontakte - unter dem Namen Chajtlina firmiert. 2015 wird diese Namensänderung offiziell: Am 5. Mai zeigt Kudrjaševa auf Facebook ein Photo ihres deutschen Aufenthaltstitels, der auf den Namen >Alina Khajtlina< lautet (Kudrjaševa 2015a). Diese Authentifizierungsstrategie erinnert an einen frühen Runet-Skandal aus dem Jahr 1997: den Fall Katja Detkina. Dabei handelte es sich, wie Evgenij Gornyj (2007: 221) ausführt, um eine virtuelle Persönlichkeit des Graphikdesigners Artemij Lebedev, was allerdings vielen Leserinnen und Lesern nicht bewusst war. Durch eine Photomontage eines Ausweises und andere Tricks von Lebedev in die Irre geführt, nahm das Publikum den virtual als reale Person wahr. Entsprechend groß war die Trauer, als Lebedev behauptete, Detkina sei bei einem Autounfall ums Leben gekommen, und entsprechend groß der Aufruhr, als schließlich die Wahrheit ans Licht kam (ebd.).

$2 \mid »$ Ich denke nicht, dass ich und meine Gedichte ein und dasselbe sind. Den zweiten Blog lesen jene, für die ich interessant bin. Hier unterhalte ich mich mit Freunden, achte nicht auf das Publikum, kann alle zum Teufel schicken, wenn mir danach ist... Warum sollte ich mich vor irgendjemandem dafür rechtfertigen, dass ich ein gewöhnlicher Mensch bin? Nein, darauf bin ich stolz.« 


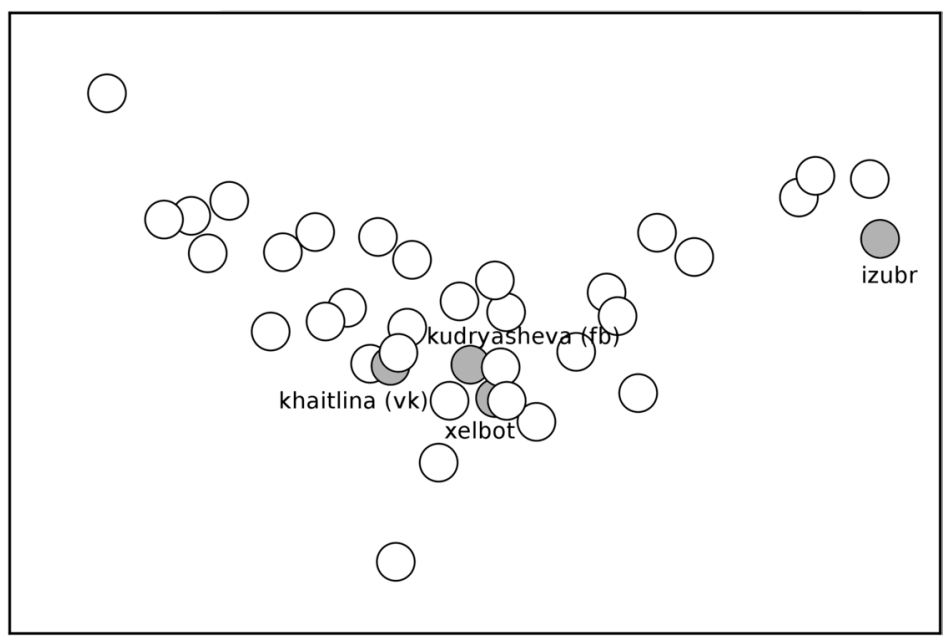

Quelle: G. H.

In diesem Zusammenhang verdeutlicht der Ausweis von Kudrjaševa / Chajtlina, auf welch brüchigem Eis solche Authentifizierungsstrategien operieren: Kudrjaševas Photo eines Ausweises taugt als Beweismittel nicht, sondern wirft bei genauerer Betrachtung weitere Fragen auf: Es fehlt der untere Rand des Ausweises, das Gesicht der Autorin wird etwas oberhalb der Nasenspitze abgeschnitten, ihre Unterschrift als >klassischer< Identitätsnachweis fehlt ganz. Anstatt Identität nachzuweisen, macht das Bild des Ausweises etwas anderes: Es liefert Bruchstücke von Identität, die das Publikum aufgreifen und zu einer Identitäts-Imagination ausbauen kann. Hierin liegt der Unterschied zwischen dem Blog 〈izubr〉 und dem Facebook-Profil: Im Fall des Blogs versucht die Autorin, solche Bruchstücke zu vermeiden, während sie diese im sozialen Netzwerk frei Haus liefert. Ihre Gedichte sind der realen Autorin aber ebenso nah - oder fern! - wie die Einträge im sozialen Netzwerk. In beiden Fällen handelt es sich um textuelle Konstruktionen; inwiefern sich diesbezüglich Kudrjaševas lyrischer Blog von ihren Profilen in verschiedenen sozialen Netzwerken unterscheidet, soll nachfolgend geklärt werden.

Dafür werden zunächst Kudrjaševas verschiedene Online-Auftritte in Beziehung zueinander gesetzt. Das »topic modeling « hilft auch in diesem Kontext, sich einen Überblick zu verschaffen. Abbildung 24 zeigt die Topic-Karte des Gesamtkorpus, auf der Kudrjaševas Online-Auftritte, quasi die Bruchstücke ihrer »gespaltenen Persönlichkeit «, hervorgehoben sind. Auffällig ist die Nähe der Profils auf Facebook, des Profils auf Vkontakte und des ŽŽ-Blogs 〈xelbot〉 zueinander, auch wenn die Blogs 
anderer Autorinnen und Autoren sozusagen >dazwischenfunken $<$. All diese OnlineAuftritte sind klar dem alltäglichen Teilkorpus zuzurechnen. Es ist zu erwarten, dass die Autorin soziale Netzwerke nutzt wie so viele andere auch, indem sie alltägliche und private Einträge veröffentlicht. Nachzuprüfen ist, wie sehr (Selbst-)Vermarktung dabei eine Rolle spielt. In den folgenden Abschnitten wird daher nachgezeichnet, welche Strategien der (Selbst-)Inszenierung Kudrjaševa auf unterschiedlichen Plattformen nutzt, wie sie mit ihrem Publikum interagiert und zu welchen Wechselwirkungen ihre vier Online-Präsenzen führen.

\section{LYRISCHER BLOG}

In der Überblicksdarstellung wurde bereits ausgeführt, dass Kudrjaševas Blog 〈izubr $>$ wie kein anderer Webauftritt im Korpus literarisch dominiert ist, während (Selbst-) Vermarktung kaum festgestellt werden kann (vgl. Seite 257). Nachfolgend werden deshalb die einzelnen Topics nicht im Detail analysiert, sondern vielmehr einzelne Gedichte und andere künstlerisch überformte Texte gezielt auf Interferenzen zwischen lyrischem bzw. Text-Subjekt und Strategien der (Selbst-)Inszenierung untersucht. Zunächst ist zu klären, warum der Blog 〈izubr〉 heißt. Die titelgebende sibirische Hirsch-Art könnte eine Anspielung an Linor Goraliks tierische (Selbst-) Inszenierungen sein, ist aber im Unterschied dazu weniger als Rolle ausgeführt. Auf die Frage, warum sie online als 〈izubr〉 auftritt, meint die Autorin: »Слово понравилось « [»Mir hat einfach das Wort gefallen«] (Obydenkin 2008). Ausschlaggebend für Kudrjaševas (Selbst-)Inszenierung ist der Hirsch insofern, als er - im Deutschen wie im Russischen - ein männliches bzw. hypermännliches Subjekt darstellt und damit potentiell ein Spiel mit Geschlechterrollen erlaubt.

Im Blog 〈izubr〉 finden sich lyrische Texte in beinahe allen Topics, besonders aber in den drei häufigsten Topics Menschen, Natur und Literarische Texte. Wie bereits erwähnt, operiert das »topic modeling « an der Textoberfläche; aus diesem Grund müssen die Ergebnisse des Modellierungsprozesses gerade bei Gedichten mit Sorgfalt interpretiert werden. Folgende Zeilen Alja Kudrjaševas etwa werden vom Algorithmus dem Topic Natur zugeordnet: »Бегите прочь, закройтесь руками, прикиньтесь сонными сурками, / Спрячьтесь под дерево, заройтесь в песок, возьмите хлеба кусок [...]« [»Lauft weg, bedeckt euch mit euren Händen, stellt euch wie schläfrige Murmeltiere, / Versteckt euch unter einem Baum, vergrabt euch im Sand, nehmt ein Stück Brot (...)«] (Kudrjaševa 2005c). Diese Zuordnung ist zwar nicht falsch, allerdings handelt es sich nicht um eine lyrische Naturbeschreibung. Die Wörter >сурок< $[>$ Murmeltier $<]$, дерево $<[>$ Baum $<]$ und $>$ песок< $[>$ Sand $<]$ bauen 


\section{Abbildung 25: Die zehn häufigsten Topics im Blog 〈izubr〉}

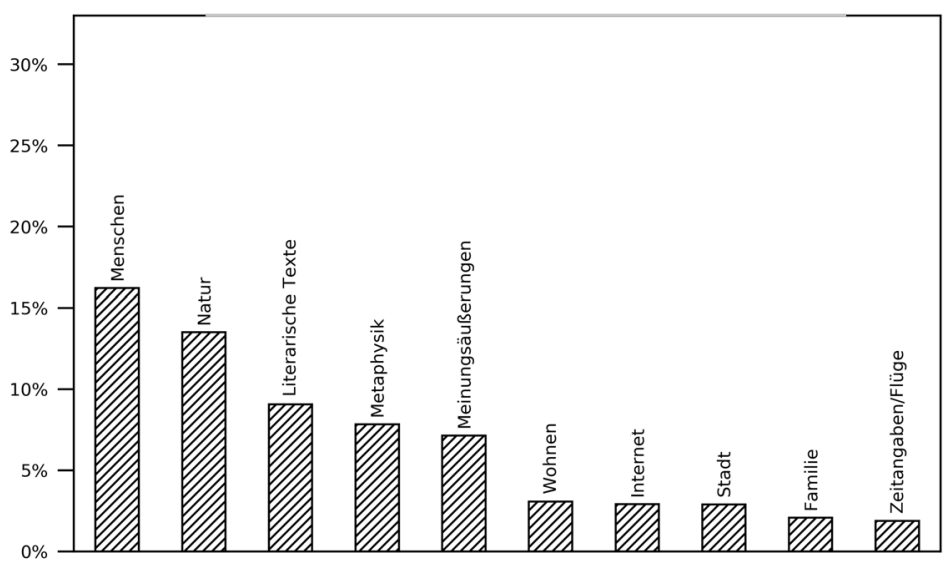

Quelle: G. H.

vielmehr eine Natur-Isotopie auf, die für einen kindlich-naiven Zugang zur Welt und einen spielerischen Umgang mit dem Alltag plädiert. Natur ist in diesem Fall kein Attribut des Inhalts, sondern der Form. Erneut zeigt sich, dass quantitative Verfahren mit qualitativer Analyse kurzgeschlossen werden müssen, um etwa den Einfluss metaphorischer Sprache miteinbeziehen zu können.

Insgesamt zeichnet sich Kudrjaševas lyrischer Blog 〈izubr〉 durch Gedichte und Kurzgeschichten aus, die einen spielerischen Umgang mit Sprache erkennen lassen. Dazu führt Kudrjaševa in einem Interview mit Dar'ja Mel'nikova aus:

Я считаю, что журнал Izubr пишет уже не человек, а именно пользователь Izubr. Это такая специальная машинка, которая не может сказать фразу, не оформив ее художественно; и которая, написав любое предложение, даже самое случайное, помнит, что его прочитают 6 тысяч человек. ${ }^{3}$ (Mel'nikova 2008a)

Die künstlerische Formulierungswut der $>$ Schreib-Maschine<〈izubr〉 schlägt sich in unterschiedlichen Genres nieder. Neben formal konservativen Gedichten finden sich experimentelle Texte, die zwar in Prosa verfasst sind, aber von Reimen durchzogen

$3 \mid$ »Ich denke, dass den Blog 〈izubr〉 nicht mehr ein Mensch schreibt, sondern der Benutzer 〈izubr〉. Das ist so eine spezielle Maschine, die keine Phrase sagen kann, ohne sie künstlerisch zu gestalten; und die sich, nachdem sie einen beliebigen Satz - selbst den allerzufälligsten geschrieben hat, daran erinnert, dass diesen sechstausend Menschen lesen.« 
werden. Zudem erinnern sie mit dem ihnen eigenen, bestimmenden Rhythmus an Poetry-Slam-Texte. ${ }^{4}$ Zwei dieser Slam-Texte sind es, die laut Kudrjaševa für den Erfolg ihres Blogs verantwortlich sind, nämlich »I ty ideš' po gorodu, i za tebja letjat babočki« [»Und du gehst durch die Stadt, und hinter dir fliegen Schmetterlinge her «] und »Ot moich dekabrej do tvoej vesny...« [»Von meinen Dezembern zu deinem Frühling...«] (Obydenkin 2008). Ersterer wurde in der Überblicksdarstellung bereits analysiert, zweiterer beginnt wie folgt:

Я работаю солнечной батареей, я в кармане оранжевом солнце грею, чтоб оно на небо взошло скорее и чесало макушки заснувших лип. Солнце ловит за пальцы меня лучами, я его приручила и отвечаю, солнце просит завтрак и выпить чаю, просит прямо внутрь его налить.

Солнцу так одиноко ходить по кругу - вот нашло, понимаешь, себе подругу, и ему всё равно - хоть любовь, хоть ругань, поболтать бы вот только о ерунде. Я его несу осторожно очень, ведь оно непоседливо между прочим и всё время выпрыгнуть хочет ночью, чтобы вдруг повсюду случился день. [.. . $]^{5}$ (Kudrjaševa 2005d)

Der Text spielt mit der Mehrdeutigkeit der 〉Solarzelle $<$ Im Russischen wörtlich 〉Sonnenbatterie<, kann dies auch als >Sonnenheizung « gelesen werden. Das Textsubjekt ist als »Freundin der Sonne « weiblich markiert, trotzdem drängt sich auch bei einer naiven Lesart keine unmittelbare Verbindung zwischen Autorin und Textsubjekt auf. In seiner Anlehnung an Fabeln oder Märchen wird der Text symbolisch aufgeladen, was dem Dokumentarischen der (Auto-)Biographie im Weg steht.

Den besonderen Reiz des Textes macht seine Musikalität aus. Diese ist wohl dem fließenden Rhythmus geschuldet, der durch die Reime aufgebaut wird: батареeŭ грею - скорее, кругу - подругу sowie очень - прочим - ночью. Manche Leserinnen und Leser haben, so schreiben sie, beim Lesen sofort eine Melodie im Kopf (Belyj

4 | Allgemein zu Poetry-Slams vgl. Preckwitz (2005) und Masomi (2012), für eine Diskussion von Authentizitätsstrategien in der »Slam Poetry« siehe Holzheimer (2014).

$\mathbf{5} \mid$ »Ich arbeite als Solarzelle, ich wärme die Sonne in einer orangenen Tasche, damit sie am Himmel schneller aufgeht und über die Wipfel der schlafenden Linden kämmt. Die Sonne erwischt mich an den Fingern mit Strahlen, ich zähmte sie und antworte, die Sonne bittet um Frühstück und eine Tasse Tee, bittet, geradewegs ins Innere sie zu gießen. / So einsam ist für die Sonne das Im-Kreis-Laufen - da hat sie sich eine Freundin, verstehst du, gesucht, und ihr ist alles egal - sei es Liebe, sei es Streit, sie möchte nur ein bisschen über Unsinn plaudern. Ich trage sie voller Vorsicht, weil sie im Übrigen rastlos ist und nachts immer herausspringen will, damit plötzlich überall Tag ist. [...]« 
2005). Mit den multimedialen Mitteln des Web könnte Kudrjaševa hier ansetzen und dem Text tatsächlich ihre Stimme verleihen, indem sie sich beim Rezitieren filmt. Dies geschieht allerdings nicht; dem Publikum werden keine zusätzlichen Persönlichkeitssplitter in die Hand gegeben.

Nicht alle Prosatexte des Blogs 〈izubr〉 sind den Slams zuzurechnen. Der folgende Eintrag über ein Wohnhaus - ein Thema, das bei Kudrjaševa immer wieder anklingt - ist weniger rhythmisch und weitaus prosaischer, aber reich an rhetorischen Figuren, vor allem Anaphern und syntaktischen Parallelismen:

Открою дверь в подъезд - темно. Затхло так. Значит, дома. Значит, четыре этажа вверх - мимо пятнистых, ободранных перил - мимо надписей на зеленых стенах мимо разбитого стекла на втором, мимо оставленного кем-то ботинка на третьем. ${ }^{6}$ (Kudrjaševa 2005e)

Einmal mehr handelt es sich um ein Sprachspiel mit einer alltäglichen Szene, die an die bereits erwähnte Ferienszene erinnert, wenn die »Mama auf der Datscha « ist. Das Publikum erfährt kaum etwas über das lyrische Subjekt, der Fokus liegt eben nicht auf der Vermittlung (auto-)biographischer Information. Die Textsubjekte der Prosa- und Slam-Einträge bleiben im Hintergrund und weisen keinen offensichtlichen Bezug zur Autorin auf. Implizit ist dieses Zurücknehmen der eigenen Person durchaus eine Strategie der (Selbst-)Inszenierung, die über die gewählten Themen Normalität vermittelt.

Im Gegensatz zu den eben genannten Prosatexten lassen sich in einigen lyrischen Texten durchaus (auto-)biographische Splitter ausmachen. Folgendes Gedicht, dessen Anfang in der Überblicksdarstellung bereits zitiert wurde, kann als Beispiel dafür dienen:

Я иду на немецкий, я знаю »Ich Bin«

Мне несложно заметить, что я всеми любим,

У меня есть улыбка, что кончается в районе ушей.

Мне не снятся кошмары, я засыпаю в метро,

Две минуты до пары и на вахте контроль,

Но я успею купить стаканчик кофе за пару грошей.

6 | »Ich öffne die Haustür: dunkel. So modrig. Das heißt: Mein Zuhause. Das heißt, vier Etagen nach oben - vorbei an fleckigen, schäbigen Geländern - vorbei an den Inschriften an grünen Wänden - vorbei am eingeschlagenen Fenster auf der zweiten Etage, vorbei an dem von irgendjemanden zurückgelassenen Schuh auf der dritten.« 
По утрам »привет«, по вечерам »пока«

И Всё будет Хорошо, я пою »Ом Мани«

Со студенческим в кармане

И со стареньким »Зенитом « в руках.

$[\ldots]$

У друзей очки, они ночуют в ПОМИ,

Они грызут колпачки и спасают мир,

Они умеют говорить слова и никому не вредить.

У одних протон, у других ДНК,

А я пою о том, чего не знаю пока,

Ничего, это можно исправить - ведь жизнь впереди.

По утрам »привет«, моя жизнь легка,

И всё будет хорошо, я пою »Ом Мани«

Со студенческим в кармане

И горячим юным солнцем в руках. ${ }^{7}$

(Kudrjaševa 2005k)

Das lyrische Subjekt ist hier optimistisch und lebensfroh, wie die »улыбка, что кончается в районе ушей « [»Lächeln, das in der Gegend der Ohren endet«] andeutet, und steht noch am Anfang des (studentischen) Lebens: »ведь жизнь впереди« [»schließlich liegt das Leben vor uns«]. Dass das lyrische Subjekt studiert, wird

$7 \mid$ »Ich gehe in den Deutschkurs, ich kenne >Ich Bin< / Mir fällt es nicht schwer zu sagen, dass ich einer bin, den alle gern haben, / Ich habe ein Lächeln, das in der Gegend der Ohren endet. / Ich habe keine Albträume, ich schlafe in der U-Bahn ein, / Zwei Minuten bis zum Unterricht und die Aufsicht wacht, / Aber ich schaffe es, eine Tasse Kaffee für ein paar Groschen zu kaufen. // Morgens >Hallo< abends >Baba< / Und alles wird Gut, ich singe >Om Mani< / Mit dem Studierendenausweis in der Tasche / und dem alten >Zenit < in den Händen // [...] Meine Freunde haben Brillen, sie übernachten im POMI, / Sie nagen an ihren Hauben und retten die Welt, / Sie können Worte sagen und niemandem schaden. / Die einen haben das Proton, die anderen die DNS, / Und ich singe von etwas, das ich noch nicht weiß, / Macht nichts, das kann man korrigieren - schließlich liegt das Leben vor uns. // Morgens >Hallo<, mein Leben ist leicht, / Und alles wird gut, ich singe >Om Mani< / Mit dem Studierendenausweis in der Tasche / Und einer heißen jungen Sonne in den Händen.«] 
anhand einer Reihe von Wörtern klar, am deutlichsten wohl anhand des »студенческий [билет]« [»Studierendenausweis «] sowie des »ПОМИ«, eines Petersburger Mathematikinstituts. Letzteres ruft in Zusammenhang mit »протон« [»Proton«] und »ДНК« $[» \mathrm{DNS} «]$ einen naturwissenschaftlichen Kontext auf, der in Kontrast zur Deutschstunde am Anfang des Gedichts steht.

Die Deutschstunde ist es auch, die einen Bezug zu Kudrjaševas (Auto-)Biographie aufbaut: Ihre Liebe zur deutschen Sprache zeigt sich in eigenen Gedichten auf Deutsch (Kudrjaševa 2012b) ebenso wie in Übersetzungen aus dem Deutschen, etwa eines Gedichtes des österreichischen Lyrikers Erich Fried (Kudrjaševa 2011f); schließlich übersiedelt die Autorin auch nach München. Ebenfalls belegt ist, dass Kudrjaševa in St. Petersburg studiert hat, die geschilderte Situation hat sie unter Umständen selbst erfahren. Zu ergänzen ist hier allerdings: Wie so viele andere auch. Dieses Gefühl, die Welt liege einem zu Füßen, der rebellische Kaffee zwei Minuten vor Unterrichtsbeginn, das alles erinnert an die Stimmung zu Studienbeginn, wenn die Abschlussarbeiten noch in weiter Ferne liegen. Auch wenn Petersburg als Ort des Geschehens klar festgelegt ist, kann wohl jede (ehemalige) Studentin und jeder Student das geschilderte Gefühl ein Stück weit nachvollziehen.

Wieder ist es ein eher allgemein gehaltener Text, der das Publikum auffordert, sich selbst im Text wiederzufinden. Die dabei eingestreuten (auto-)biographischen Splitter sind wenig an der Zahl und für das Gedicht unbedeutend; auf »любим « hätte sich auch ein anderer Reim finden lassen, das Spiel mit deutschen Wörtern, das Iosif Brodskij in »Dva časa v rezervuare« [»Zwei Stunden im Reservoir«] (1965) durch ein ganzes Gedicht getragen hat, beschränkt sich hier auf die zweite Verszeile. Das buddhistische Mantra »Om mani« ist wesentlich präsenter. Es ist Teil des mit »По утрам >привет $<\ll[»$ Morgens $>$ Hallo $<\ll]$ beginnenden $>$ Refrains $<$, der im obigen Zitat einmal, im gesamten Gedicht dreimal vorkommt. Das Mantra wird damit im wahrsten Sinne des Wortes gebetsmühlenartig wiederholt, steht als sprachliche Anspielung im Mittelpunkt und drängt das Deutsche und damit einen (auto-)biographischen Bezugspunkt in den Hintergrund.

Auf eine ähnliche Art und Weise >persönlichく sind jene Gedichte in Kudrjaševas Blog, die das Scheitern einer Beziehung thematisieren. Trotz des scheinbar persönlichen Themas werden allgemeine Erfahrungen geschildert. So gibt es auch in folgendem Gedicht mit dem Titel pis'mo sčast'ja [glücksbrief], das aufgrund seiner Länge nur in Ausschnitten zitiert wird, kaum Verweise auf eine konkrete (auto-) biographische Situation: 
Девочка обнимает тебя, будто анаконда, спрашивает, как назвали, как родила. Она тебя, в общем, забыла почти рекордно - два дня себе поревела и все дела. Потом, конечно, неделю всё письма жгла.

И месяц где-то спать еще не могла.

$[\ldots]$

А ей говорили - дура, следующего так просто не отпускай.

Ты наори на него и за волосы потаскай.

А то ведь видишь - какая теперь тоска,

Поздравляешь её »здоровья, любви, вина«

А её так тянет ответить: »Пошел ты на«

И дергаться, как лопнувшая струна.

А я сижу в ночи, и собака лает, так жалобно - куда уж там соловью, Дедка Мороз, я пишу тебе соком лайма, кефирчиком залью и дымком завью. Будешь читать - пожалуйста, пожелай мне вырубить это чертово ай-си-кью. Столько народу в четыре утра в онлайне - страшно за их налаженную семью. 8

(Kudrjaševa 2007j)

$8 \mid »$ Das Mädchen hat rote Haare, eine grüne Jacke, einen blauen Himmel, gelockte Wolken. / Das Mädchen raucht übrigens schon ein halbes Jahr lang nicht, Joggen, eine Tasse frischer Milch / Das Mädchen umarmt dich, als sei sie eine Anakonda, fragt, wie ihr's genannt habt, wie die Geburt war. / Sie hat dich im Allgemeinen fast rekordverdächtig vergessen - hat sich zwei Tage ausgeheult - und aus. / Dann hat sie freilich eine Woche lang alle Briefe verbrannt. / Und wohl einen Monat lang konnte sie nicht schlafen. // [...] Und ihr wurde gesagt - Dummkopf, den nächsten lässt du nicht so leicht laufen. / Schrei ihn an und zieh ihn an den Haaren. / Du siehst ja - welche Sehnsucht, / Du wünschst ihr >Glück, Liebe, Wein</ Und sie ist versucht zu antworten: >Scher dich zum Teufel<, Und zu zucken wie eine gerissene Saite. // [...] Und ich sitze in der Nacht, und ein Hund heult so kläglich - was willst du da mit einer Nachtigall, / Väterchen Frost, ich schreibe dir mit Limettensaft, gieße nach mit Kefir und lasse den Rauch kräuseln. / Wenn du's liest - bitte, drück mir die Daumen, dass ich dieses teuflische Ai-si-kju ausreiße. / Wie viele Menschen um vier Uhr früh online sind - wie schrecklich für ihre fein säuberlich organisierte Familie.« 
Zunächst wird von einem Mädchen in der dritten Person berichtet, das eine Trennung zum Anlass nimmt, ihr Leben zu verändern. Die roten, lockigen Haare könnten auf die Autorin verweisen, weitere als solche erkennbare (auto-)biographische Anspielungen gibt es nicht. Der Text wendet sich mit seinem $>\mathrm{Du}<$ an den ehemaligen Liebhaber. Dabei wird ein Kontrast zwischen Außen- und Innensicht aufgebaut: Nach außen hin zeigt das Mädchen nach der Trennung Stärke, lebt gesünder, wünscht ihrem ehemaligen Partner alles Gute - die Anakonda-Umarmung deutet in einer Schlüsselstelle aber schon an, dass diese Stärke nur Fassade ist. Denn einerseits stellt diese einen erdrückenden Angriff dar und keine freundschaftliche Geste. Gleichzeitig kann das Mädchen nicht loslassen und schlingt sich zumindest in Gedanken immer noch um den Exfreund. Die folgenden Zeilen bestätigen diese Einschätzung.

Die letzte Strophe hebt sich heraus aus dieser Situation. Plötzlich gibt es ein explizites >Ich<, das spricht; es vertreibt sich eine schlaflose Nacht damit, vor dem Computer zu sitzen und sich über die Gemeinschaft der Internetsüchtigen zu wundern. Hier ergibt sich eine Verbindung zwischen dem lyrischen Subjekt und der Autorin: Kudrjaševa sitzt beim Veröffentlichen des Gedichts ebenfalls vor dem Computer, auf dem das Chatprogramm ICQ [»ай-си-кью«] - »I seek you « - laufen könnte. Einschränkend ist anzumerken, dass das Gedicht laut $\check{Z} Z \check{Z}$ um 22:34 veröffentlicht worden ist, nicht um vier Uhr morgens; die letzte Strophe könnte aber die Entstehungsbedingungen des Textes umschreiben, nicht die Publikationsbedingungen.

Das rothaarige Mädchen, das >Ichく und Kudrjaševa bilden ein loses Dreieck, in dem die Beziehungen betont ungewiss bleiben: Zwar wird die Liebesthematik der >Mädchen<-Strophen auch in der letzten Strophe mit der Nachtigall aus Romeo und Fulia sozusagen im Vorbeigehen erwähnt. Dominant ist aber das Hundegebell, das den Vogelgesang überdeckt. Als weiteres verbindendes Element schlängeln sich Zischlaute sowie das $>\mathbf{s}<$ durch das gesamte Gedicht, greifen das Bild der Anakonda wieder auf und binden die letzte Strophe an den Rest. Genannt seien hier zwei Beispiele: »Дево чка, кстати, полгода уже не курит, пробежка, чашка свежего молока« sowie »Будешь читать - пожалуйста, пожелай мне вырубить это чертово ай-си-кью. «. Die »gelockten Wolken« und der »kräuselnde Rauch« folgen ebenfalls einer schlangenhaften Form bzw. Bewegung. Die Schlangenmetaphorik wird auf formaler Ebene durch schlangenhaft lange Verse mit bis zu dreißig Silben fortgesetzt und äußert sich auch in zahlreichen Haufenreimen, etwa отпускай - потаскай тоска, вина - ты на - струна und in der letzten Strophe соловью - завью - айси-кью - семью. Die letzte Strophe hebt sich inhaltlich vom restlichen Gedicht ab, dieser Unterschied wird aber durch die Form abgeschwächt. Dadurch rücken das rothaarige Mädchen und das >Ich< der letzten Strophe wieder enger zusammen. 
Die durch die letzte Strophe suggerierte Verbindung zwischen Internetkommunikation und Liebesbeziehung wird in einem anderen Gedicht weiter ausgeführt. Der Text spielt in seinem Titel »Devočka, živuščaja v seti« [»Das Mädchen, das im Netz lebt «] auf ein Lied der Sängerin Zemfira an:

Ax, как хочется жить в виртуальности - только так,

Чтобы видели лишь нарисованное лицо,

Чтобы мысли бежали буковками по листам -

Не живыми словами, не болью, в конце концов...

Здесь досталось обиды поровну - им и нам,

Здесь закрыли возможность ответов - и кончен спор

Здесь всё просто - поставил прочерк напротив имени. . .

А потом - не знаю, мы с тех не встречались пор...

Я потом пожалею и буду тебя искать,

На сухом асфальте вглядываться в следы,

Я - потом... А сейчас и ненависть, и тоска,

И обида. На то что, мог избежать беды

И ладони мокрые от лица отвести,

И отбросить в сторону шпагу, палаш, пращу...

И стучаться в дверь, чтобы просто сказать: »Прости«

В то же время думая: »Сам уже не прощу. 9

(Kudrjaševa 2004c)

$\mathbf{9} \mid$ »Ach, wie gerne würde ich in der Virtualität leben - nur so, / Dass sie einzig das gezeichnete Gesicht sehen, / Dass die Gedanken als Buchstaben über die Seiten laufen - / Nicht als lebendige Worte - nicht als Schmerz, schlussendlich ... // Hier ist die Kränkung gleichverteilt zwischen ihnen und uns, / Hier haben sie die Möglichkeit zu antworten geschlossen - und der Streit verstummt / Hier ist alles einfach - ich habe neben den Namen einen Strich gesetzt... / Und dann - ich weiß nicht, wir haben uns seit damals nicht gesehen ... // Und dann wird es mir Leid tun und ich werde dich suchen, / Auf dem trockenen Asphalt die Spuren lesen, / Dann - ich ... aber jetzt: Hass, Sehnsucht, / Kränkung. Dafür, dass ich dem Leid entfliehen konnte // Und die nassen Handflächen vom Gesicht nehmen, / Und den Degen zur Seite werfen, den Pallasch, die Steinschleuder... / Und an die Tür klopfen, um einfach zu sagen: >Verzeih / Gleichzeitig zu denken: ১Selbst verzeihe ich nicht mehr.«« 
Abbildung 26: Kudrjaševas Stimmung ist nicht die beste.

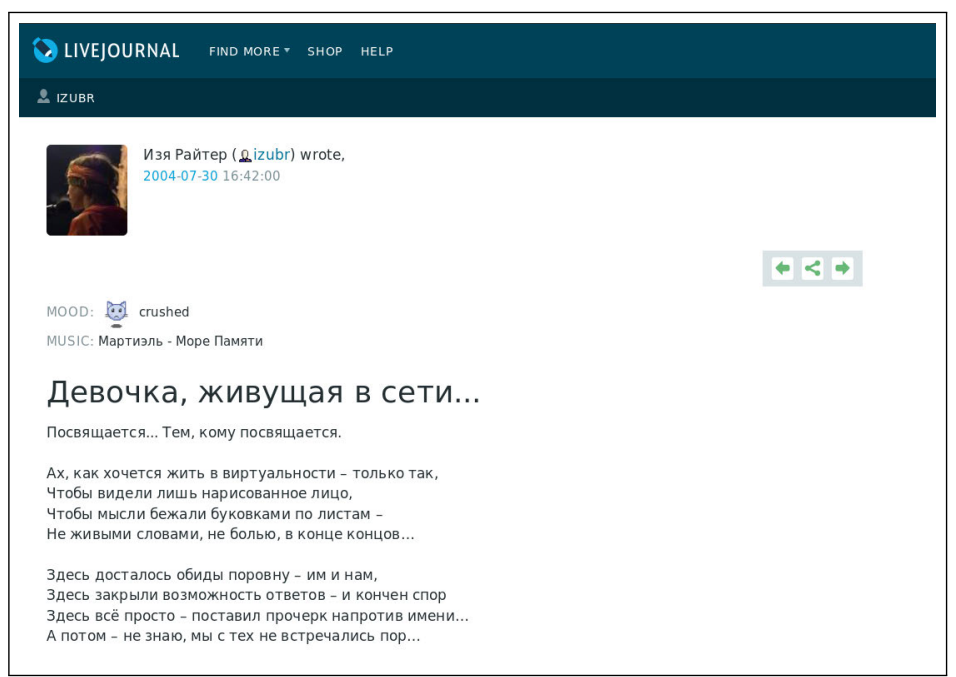

Quelle: Kudrjaševa 2004c

Die ersten beiden Strophen des Gedichts singen der Virtualität ein Loblied: Abgekoppelt von den »живы[е] слова[]« [»lebendige Worte«] lebt es sich leichter. Der potentiell unangenehme Kontakt $\mathrm{zu}$ anderen Menschen kann leicht unterbunden werden, indem Antwortpostings verunmöglicht werden. Ehemalige Freunde lassen sich schnell aus der Freundesliste entfernen und verschwinden auf Nimmerwiedersehen. Menschen werden im Netz automatisch auf ihr »нарисованное лицо « [»gezeichnetes Gesicht «] und ihren Namen reduziert, alles andere bleibt verborgen.

Erst in der dritten und vierten Strophe wird deutlich, dass erneut eine gescheiterte Beziehung thematisiert wird. Im Unterschied zu den virtuellen Zeichen der ersten beiden Strophen stehen nun metonymische Körperzeichen im Vordergrund: Spuren auf dem Asphalt, Tränen, Klopfen und nicht zuletzt Worte. Nach der Lektüre der letzten beiden Strophen wird klar, dass der eingangs geäußerte Wunsch einem kurzsichtigen Eskapismus geschuldet ist: Um dem Trennungsschmerz entfliehen zu können, möchte das lyrische Subjekt, überspitzt formuliert, in einer Welt ohne Gefühle leben, in einer Welt, in der zwischenmenschliche Kontakte medial vermittelt werden und damit überaus brüchig sind. Es wird eine Hierarchie aufgebaut, indem die Virtualität als frei von allen Gefühlen beschrieben wird. Erst im >echten L Leben wird die Interaktion der leblosen Schriftzeichen von der Interaktion der lebendigen Körper abgelöst. Bei allem Leid, das die >Wirklichkeit< mit sich bringen mag, zieht das lyrische Subjekt diese der Virtualität. Das Gedicht ist insofern programmatisch, 
als Kudrjaševa sich ein solches Leben im Virtuellen geschaffen hat. Avatarbild und Nick 〈izubr〉 bilden ebenso eine Barriere wie die lyrischen Subjekte ihrer Gedichte. Sollte eine Online-Interaktion zu persönlich werden, kann sich die Autorin hinter diese doppelte Mauer aus technischen Bedingtheiten und literarischen Konstrukten zurückziehen. In diesem konkreten Fall geht Kudrjaševa allerdings den umgekehrten Weg und stellt mittels der Paratexte persönliche Bezüge her.

Über dem Eintrag prangt groß: »MOOD: crushed«, verstärkt um ein traurig dreinblickendes Katzengesicht (Abbildung 26). Nach dem Titel folgt eine Widmung: »Посвящается... Тем, кому посвящается.« [»Gewidmet... Denjenigen, denen es gewidmet ist.«]. Die Formulierung impliziert, dass es eine bestimmte Person gibt, die sich angesprochen fühlen sollte, die der Sprecher aber nicht nennen möchte. In Verbindung mit einem Gedicht über eine gescheiterte Beziehung nährt eine solche Einleitung Spekulationen. Direkt im Anschluss an die letzte Strophe folgt der Satz: »Не шедевр, простите. Но мысли.« [»Kein Meisterwerk, verzeiht. Aber Gedanken.«]. Dieser Satz ist als Kommentar nicht extra hervorgehoben, könnte also auch den letzten Satz des Gedichtes darstellen.

In formaler Hinsicht wird eine Verbindung zwischen Gedicht und Kommentar unterstrichen: Zwar gibt es kein regelmäßiges Metrum, jede Verszeile beginnt aber mit einem Anapäst; der abschließende Kommentar besteht wiederum aus einem dreihebigen Anapäst. Bei der Lektüre kommt es am Ende also nicht zu einem rhythmischen Bruch, der Text bleibt homogen. Auch die Widmung fügt sich im Übrigen in dieses Schema ein. Gleichgültig, ob der letzte kommentierende Satz nun Teil des Gedichts ist oder nicht, durch ihn erscheinen die Strophen in neuem Licht: Das Gesagte sei nicht als Kunstwerk gedacht, sondern solle die Gedanken der Autorin transportieren. Ein allgemein formuliertes Gedicht wird hier durch verschiedene kurze Paratexte in die Nähe (auto-)biographischer Praktiken gerückt.

Solche paratextuellen (Selbst-)Inszenierungen kommen bei Kudrjaševa immer wieder vor. Die Kürze der Texte erschwert dabei elaborierte Strategien; in der Regel wird die Phantasie des Publikums angeregt, indem ein persönlicher Hintergrund des jeweiligen Gedichtes suggeriert wird. Einem weiteren Gedicht über eine gescheiterte Beziehung ist etwa folgender Satz nachgestellt: »Извините, вырвалось. [»Entschuldigt, das ist mir rausgerutscht «] (Kudrjaševa 2005b). Auch ein Titel kann die Funktion eines Metakommentars übernehmen. Die bereits erwähnte Anspielung auf Bulat Okudžava ist übertitelt mit »Skoro sovsem na verlibr perejdu...« [»Bald gehe ich ganz zum vers libre über...«] (Kudrjaševa 2004b). Nachdem das Gedicht tatsächlich in einem freien Rhythmus verfasst worden ist, drängt sich die Vermutung auf, die Autorin reflektiere im Titel lyrische Positionsentscheidungen. Da gleich in den ersten beiden Verszeilen ein $» я$ « spricht, scheint das lyrische Subjekt nahtlos an das 
Subjekt im Titel anzuschließen. (Selbst-)Inszenierung braucht allerdings nicht zwingend ein explizites »я«, auch ein Gegenüber kann als Projektionsfläche dienen. Im Gedicht »(izlišnaja didaktika) dočeri« [»(überflüssige didaktik) für die tochter «] mutiert ein Gespräch zum Selbstgespräch, das Selbst entsteht gleichsam in der Reflexion des Lacan'schen Spiegels (Lacan 1966):

Не дай тебе бог заедать алкоголь анальгином,

Не дай тебе бог засыпать в незнакомой постели,

Не дай вам господь представать перед богом нагими

Пред богом, пред утром, где стекла едва запотели,

Не дай тебе бог говорить о любви в смсках,

И в письмах читать между строк в коридорах осенних.

Не дай тебе бог не найти подходящего места,

Точнее найти - и все время жалеть о соседнем.

И если ты будешь, а я ведь уверена - будешь,

Бродить по ночам, безответно по городу шляться.

Дай бог тебе, милая, в целом не выбиться в люди,

А вбиться в себя, безнадежно, по самую шляпку.

И если ты стерпишь - а я уже знаю, не стерпишь

Мои дидактически точные фразы »как в школе«,

Поверь, что шиповник был тоже лохматым и терпким,

И так же кололся. И так же болели уколы.

И тот же минор и мажор - будто в »Хава Нагиле«,

И те же обиды - настолько сильнее меж прочих.

Не дай тебе бог заедать алкоголь анальгином

А все остальное, мне кажется, будет попроще. ${ }^{10}$ (Kudrjaševa 2011d)

10 | »Gebe Gott, dass du nach Analgin keinen Alkohol trinkst, / Gebe Gott, dass du nicht in einem unbekannten Bett aufwachst, / Gebe euch der Herr, dass ihr nicht nackt vor Gott stehen müsst / Vor Gott, vor dem Morgen, wenn die Fenster ein wenig beschlagen sind, // Gebe Gott, dass du nicht über die Liebe sprechen musst in SMSen, / Und nicht in Briefen zwischen den Zeilen lesen musst in herbstlichen Korridoren. / Gebe Gott, dass du einen passenden Platz findest, / Genauer: dass du ihn findest - doch dir die ganze Zeit den daneben wünschst. // Und wenn du durch die Nacht streichen und unerwidert in der Stadt herumlungern wirst, 
In einer Allusion auf Puškins »Ne daj mne bog sojti s uma« [»Gebe Gott, dass ich nicht verrückt werde«] (1833) wendet sich das lyrische Subjekt an seine Tochter und bittet diese, die eigenen Jugendsünden nicht zu wiederholen. Über die Beschwörungsformeln und ihre Wiederholungen ergibt sich eine Verbindung zu dem bereits erwähnten Gedicht »I differenciruet čaj...(c)« [»Und der Tee differenziert...(c)«] über die Studienzeit, in dem ein buddhistisches Mantra mehrmals wiederholt wird (Kudrjaševa 2005k). Während das lyrische Subjekt dort allerdings die Freiheit und das Leben genießt, ist es hier um das Wohl der Tochter besorgt. Über die Gottesanrufungen klingen christliche Vorstellungen von Schuld an. Erst in der letzten Strophe wird die Stimmung fröhlicher, nicht zuletzt durch das jüdische Feierlied Hava Nagila. Mit einer vorsichtig optimistischen Verszeile klingt das Gedicht aus: »A вce остальное, мне кажется, будет попроще.« [»Und alles andere, scheint mir, wird leichter sein.«].

Die sechs Jahre, die zwischen den beiden eben genannten Gedichten liegen, erklären ein Stück weit die veränderte Perspektive auf Jugendsünden. Ob Kudrjaševa tatsächlich unangenehme Bekanntschaft mit dem Beruhigungsmittel Analgin geschlossen hat, ist dabei nebensächlich, jedenfalls ergibt sich eine Alliteration mit >Alkohol<. Vielleicht ist es auch nur ein netter Zufall, dass sich das hier tonangebende Analgin mit dem »Ich bin« des früheren Gedichtes reimt; ein gewisses Kokettieren mit einem (auto-)biographischen Hintergrund kann beiden Texten jedenfalls nicht abgesprochen werden. Auch wenn Kudrjaševa diesen Eindruck über Meta- bzw. Paratexte verstärkt, bleibt ihr stets die erwähnte doppelte Schichtung aus lyrischem Subjekt und virtueller Persönlichkeit als Rückzugsort und Ausweg.

Im Laufe der Zeit steigt die Zahl an (auto-)biographisch gerahmten Prosatexten im Blog 〈izubr〉, beispielsweise schreibt Kudrjaševa gerne über ihren Kater (Kudrjaševa 2007e, Kudrjaševa 2008c) und publiziert entsprechende Photos. Die Autorin verspürt offensichtlich das Bedürfnis, aus ihrem Leben zu erzählen, sieht aber in der Lyrik keinen geeigneten Platz dafür. Aufschlussreich bezüglich ihrer (Selbst-)Inszenierung ist die Tatsache, dass das Publikum diese persönlichen Einträge nicht gou-

/ und ich bin mir sicher - du wirst. / Gebe Gott, meine Liebe, dass du im Ganzen nicht in gesellschaftliche Höhen vordringst, / Sondern zu dir selbst, hoffnungslos, Hals über Kopf. // Und wenn du meine didaktisch genauen Phrasen > wie in der Schule< ertragen musst / und ich weiß schon - du erträgst die nicht, / Glaube daran, dass die Hagebutte auch struppig und herb war, / Und gestochen hat. Und so schmerzten die Spritzen. // Und dieses Moll und Dur - gleich wie in >Hava Nagila<, / Und die gleichen Kränkungen - um soviel stärker als die früheren. / Gebe Gott, dass du nach Analgin keinen Alkohol trinkst / Und alles andere, scheint mir, wird leichter sein.« 
tiert. Es wurde bereits mehrfach erwähnt, dass die allgemein gehaltenen Gedichte von den Leserinnen und Lesern häufig auf sich selbst bezogen werden. Dies ist bei Einträgen zu spezifischen Situationen, die zudem Lejeunes »pacte autobiographique« folgen und damit eine klar umrissene Autorinnenpersönlichkeit haben, nur schwer möglich.

Im Gegensatz zu den meisten Beispielen dieser Studie, bei denen das Persönliche Anreiz ist, die Blogs zu besuchen, dienen Kudrjaševas Gedichte den Leserinnen und Lesern als Raum für eine eigene (Selbst-)Inszenierung. Kudrjaševa möchte trotzdem nicht darauf verzichten, persönliche Einträge zu verfassen, was schließlich in einer $>$ Persönlichkeitsspaltung < mündet: Dem lyrischen Blog 〈izubr〉 wird der (auto-)biographische Blog 〈xelbot〉 zur Seite gestellt. Wie sich diese beiden Blogs zueinander verhalten, wird im nächsten Unterkapitel herausgearbeitet.

\section{(AUTO-)BiogRAPHISCHER BLOG}

Den Blog 〈xelbot〉 gibt es seit 11. September 2005, er ist damit knapp zwei Jahre jünger als $\langle$ izubr $\rangle$. Am 13. September 2005 veröffentlicht Kudrjaševa folgendes Zitat interessanterweise im Blog 〈izubr $\rangle$ :

Позвольте представить вам своё второе »я« - 〈xelbot $\rangle$. В последнее время я как-то стала писать слишком много скучного. [...] И тут стукнуло у меня в глове [sic] это самое второе и сказало: »Так я же - второе. И нефиг нас перемешивать.« В том журнале будет то самое, чем я по сути являюсь - нервная обидчивая девочка 17 лет от роду. А то есть: нытье, лытдыбры, пафос, объявления, просьбы, зарисовки, жалобы... [...] Нефильтрованное. Вот зачешется у 〈izubr〉 левая пятка, поймет она [sic!], что миру стоит об этом знать - так тут же 〈xelbot〉 напишет. ${ }^{11}$ (Kudrjaševa 2005g)

Bemerkenswert ist, dass Kudrjaševa die (Selbst-)Inszenierung als (männlicher) 〈izubr $\rangle$ durchbricht und explizit von »она« [»sie«] schreibt. Dieser Konzeption folgend,

$11 \mid$ »Erlauben Sie mir, Ihnen mein zweites >ich〈 vorzustellen:〈xelbot〉. In letzter Zeit habe ich zu viel Langweiliges geschrieben. [...]. Da klopfte eben dieses zweite >ich $<$ an und sagte: >Also ich bin ja das zweite. Und keinesfalls kann man uns vermischen. $<$ In jenen Blog kommt dieses >ich <, das ich im Grunde bin - ein nervöses, empfindliches Mädchen von siebzehn Jahren. Das heißt: Gejammer, lytdybr, Pathos, Erklärungen, Bitten, Skizzen, Beschwerden... [...] Ungefiltertes. Wenn 〈izubr〉s linke Ferse juckt, und sie [sic!] denkt, die Welt soll das erfahren - dann schreibt $\langle$ xelbot $\rangle$ darüber.« 
Abbildung 27: Die zehn häufigsten Topics im Blog 〈xelbot〉

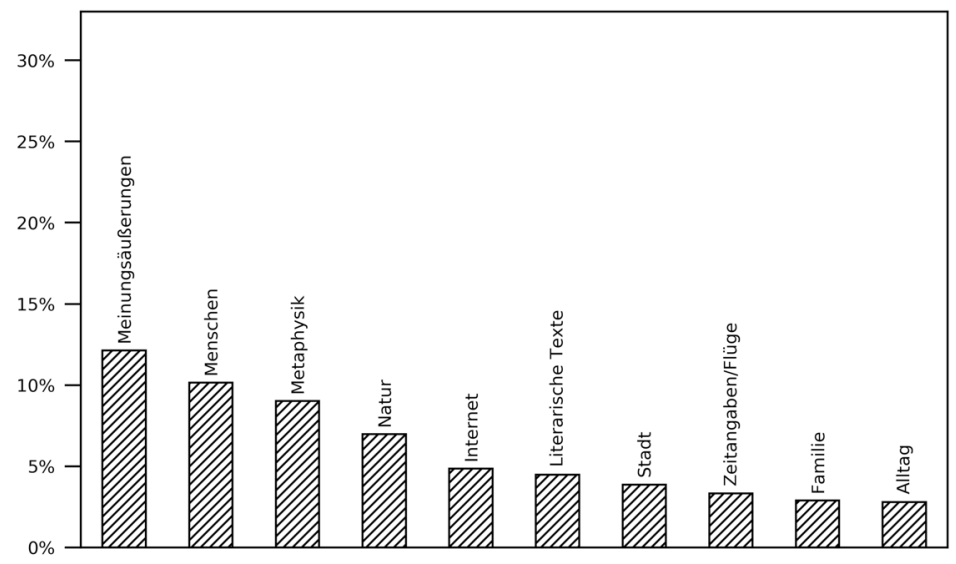

Quelle: G. H.

beginnt $\langle$ xelbot $\rangle$ nach einem kurzen Willkommenseintrag mit einem sintimen $<$ Geständnis: »C метро я состою в близких, можно даже сказать, интимных отношениях « [»Zur U-Bahn habe ich ein enges, man könnte sogar sagen, intimes Verhältnis«] (Kudrjaševa 2005h). Hier wird schon deutlich, dass sich das >Ungefilterte mehr auf die Gemachtheit der Texte bezieht, weniger auf die (Selbst-)Inszenierung. Keinesfalls wird versucht, ein ungefiltertes Bild von Kudrjaševa zu konstruieren.

Trotz des an sich klaren Konzepts ergibt sich eine strikte Trennung zwischen den beiden Blogs erst im Laufe der Zeit. Gewisse Tendenzen sind allerdings von Anfang an erkennbar: 〈xelbot〉 ist tatsächlich prosaischer, enthält mehr (auto-)biographische Einträge als Lyrik. Dies soll jedoch nicht heißen, dass 〈xelbot〉 gänzlich frei von Gedichten ist. Aufgrund seiner thematischen Mischung ist er den alltäglichen Blogs zuzurechnen, wie Abbildung 24 auf Seite 263 zeigt. Die alltägliche Ausrichtung des Blogs 〈xelbot〉 zeigt sich schon im erstplatzierten Topic Meinungsäußerung, das im Blog 〈izubr〉 auf Platz fünf liegt. Zu diesem Topic gehören Texte mit persönlicher Ausrichtung, etwa Gedanken zum Erwachsenwerden (Kudrjaševa 2011a), eine Februars-Depression (Kudrjaševa 2010a) und verschiedene Einträge, die in Zusammenhang mit Kudrjaševas Studium stehen (Kudrjaševa 2011c, Kudrjaševa 2010c). Wie wichtig ihr die Universität ist, zeigt ein Eintrag über den >Tag der offenen Tür<, den sie mit »Pro ljubimoe« [»Über das Liebste«] betitelt (Kudrjaševa 2011c).

Im Gegensatz zum Blog 〈izubr〉 rutscht das dort erstplatzierte Topic Menschen im Blog $\langle$ xelbot $\rangle$ auf Platz zwei ab, auch unterscheiden sich die entsprechenden Tex- 
te beträchtlich: Sind es im lyrischen Blog vornehmlich Gedichte, so wird das Topic im Blog 〈xelbot〉 durch kurze, literarisch überformte Episoden definiert. Eine Straßenszene vom Petersburger Nevskij Prospekt (Kudrjaševa 2005l) kommt ebenso vor wie Nacherzählungen von Träumen (Kudrjaševa 2010b) und Katzengeschichten mit Photo (Kudrjaševa 2008b). Im Topic Metaphysik (Platz drei) finden sich wieder Einträge zu Kudrjaševas Studium der Sprachwissenschaft, etwa zu dessen erfolgreichem Ende, mit dem die Autorin etwas zu kämpfen hat (Kudrjaševa 2012h). Solche >therapeutischen< Einträge verfasst sie immer wieder, beispielsweise bei schlechter Laune (Kudrjaševa 2005n). In diesen Momenten, in denen Kudrjaševa auf ihre Gefühle Bezug nimmt, erweckt $\langle$ xelbot〉 tatsächlich einen »ungefilterten« Eindruck.

Die Position des Topics Natur auf Platz vier erinnert an viele andere Blogs: Hier tauchen verschiedene Reiseberichte auf, etwa von der Krim 2007, ausgeschmückt mit entsprechenden Photos (Kudrjaševa 2007f). Die Gedichte mit Naturmetaphorik, wie sie 〈izubr〉 prägen, kommen hier nicht vor. Dominanter ist im (auto-)biographischen Blog dafür das Topic Internet (Platz fünf). Hier finden sich Meta-Einträge über den Blog; thematisiert werden öffentliche und private Einträge (Kudrjaševa 2008a). Daneben reflektiert Kudrjaševa über den Blog als Publikationsmedium. Nachdem ihr Slam-Text »I ty ideš' po gorodu, i za tebja letjat babočki« in kurzer Zeit sehr viele Leserinnen und Leser erreicht, die neben 〈izubr〉 auch 〈xelbot〉 entdecken, fühlt sich Kudrjaševa zu einer Feststellung veranlasst:

Этот журнал - реально совершенно лытдыбровый. [.. .] Ничего реально интересного тут нет [. . .]. Ни креатиффа, ни красивостей... Я просто смотрю на полтысячи читающих и ничего не понимаю. ${ }^{12}$ (Kudrjaševa $2007 \mathrm{~d}$ )

Zumindest in diesem Fall ist die Aufgabenteilung klar geregelt: 〈izubr〉 veröffentlicht das Gedicht, 〈xelbot〉 den Kommentar darüber. Die plötzliche Popularität des lyrischen Blogs wirkt sich dabei auch auf das »lytdybr «〈xelbot〉 aus. Dort versammeln sich die (wenigen) lyrischen Texte vorwiegend im Topic Literarische Texte (Platz sechs). So veröffentlicht Kudrjaševa ihr Lieblingsgedicht, das die ŽŽ-Bloggerin Asja Anistratenko verfasst hat (Kudrjaševa 2010d); es gibt aber auch eigene Gedichte (Kudrjaševa 2011b, Kudrjaševa 2007b). Ergänzend kommen literarisch überformte (auto-)biographische Texte vor, etwa über ein Treffen im Freundeskreis: »Прозрачный вечер и фонари сквозь кружевные листья. / Музыка. / Обнять на проща-

$12 \mid »$ Dieser Blog - ist echt ein komplettes lytdybr. [...] Hier gibt es nichts wirklich Interessantes [...]. Weder ein kreatiff, noch irgendwas Schönes... Ich starre einfach auf fünfhundert Lesende und verstehe gar nichts« 
ние пять человек [...]« [»Ein klarer Abend und Laternenschein durch Blätter aus Spitze. / Musik. / Zum Abschied fünf Leute umarmen (...)«] (Kudrjaševa 2005i).

Die folgenden vier Topics Stadt (Platz sieben), Zeitangaben/Flüge (Platz acht), Familie (Platz neun) und Alltag (Platz zehn) erinnern in ihrer Zusammensetzung an das alltägliche Teilkorpus: Präsentiert werden Geschichten aus dem täglichen Leben:

\section{Вхожу в дом.}

На лестнице стоит совок. Большой. Похожий на сандалию древнего римлянина.

Этажом выше стоит швабра.

Этажом выше стоят сапоги резиновые обыкновенные.

Этажом выше живу я.

Теперь мне нужно понять, какую роль я исполняю в этой цепи аксессуаров.

Видимо, веро [sic!] мусорное, протекающее. ${ }^{13}$ (Kudrjaševa 2005m)

Dies erinnert an die bereits erwähnten Wohntexte im Blog 〈izubr〉 (Kudrjaševa 2005e, Kudrjaševa 2005a). Allerdings fungiert 〈xelbot $\rangle$ nicht - wie vermutet werden könnte - als Steinbruch für lyrisches Material. Vielmehr ist der kurze Alltagstext Monate nach den beiden lyrischen Texten veröffentlicht worden.

Einen Unterschied zum lyrischen Blog stellt das Fehlen von Liebesgeschichten und Beziehungskatastrophen im Blog 〈xelbot〉 dar. Vielleicht ist dieses Topic zu persönlich, um ohne den Schutz der doppelten Schichtung aus lyrischem Subjekt und virtueller Persönlichkeit thematisiert zu werden; vielleicht ist es Kudrjaševa aber auch wichtig, vor allem kunstvoll über diese Themen zu schreiben. Das bis auf wenige Ausnahmen zu konstatierende Fehlen von >persönlichen \& Einträgen im (auto-) biographischen Blog zeigt erneut, dass die Trennungslinien zwischen 〈izubr〉 und $\langle$ xelbot〉 nicht entlang der Dichotomie öffentlich - privat verlaufen. Der Unterschied besteht vielmehr in verschiedenen Graden an Literarizität. Diesbezüglich erscheint $\langle$ xelbot〉 tatsächlich etwas »ungefiltert «. Kudrjaševa folgt der Konzeption ihres zweiten Blogs allerdings nicht konsequent. Ebenso, wie 〈izubr〉 (auto-)biographische Einträge enthält, finden sich in 〈xelbot $\rangle$ Gedichte.

$13 \mid$ »Ich gehe ins Haus. / Auf der Stiege steht eine Kehrschaufel. Eine große. Erinnert an die Sandale eines Alten Römers. / Eine Etage höher steht ein Wischmopp. / Eine Etage höher stehen gewöhnliche Stiefel aus Plastik. / Eine Etage höher wohne ich. / Jetzt soll ich begreifen, welche Rolle ich in dieser Kette von Gegenständen spiele. / Offensichtlich die eines tropfenden Mistkübels.« 
Abbildung 28: Die zehn häufigsten Topics in Kudrjaševas VK-Profil

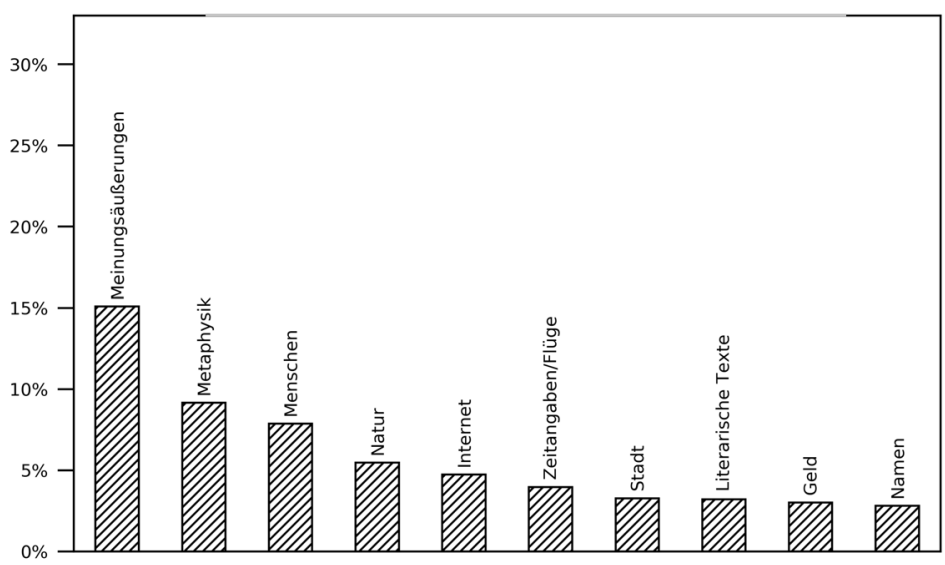

Quelle: G. H.

Abbildung 29: Die zehn häufigsten Topics in Kudrjaševas Facebook-Profil

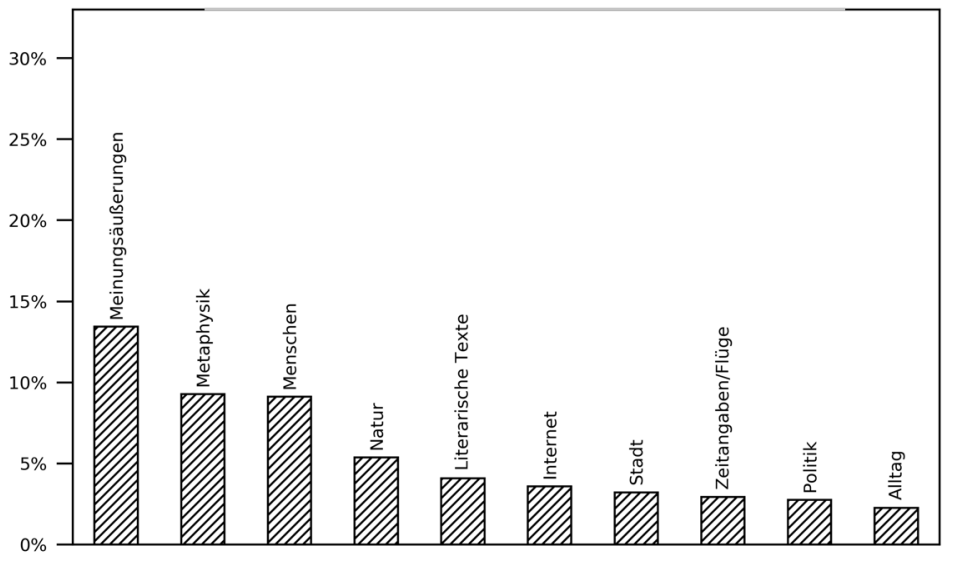

Quelle: G. H. 


\section{Soziale NetzWerke}

Neben ihren beiden $\check{Z} Z \check{Z}$-Blogs hat sich Kudrjaševa auch in den sozialen Netzwerken Facebook und Vkontakte Profile eingerichtet; dies allerdings unter ihrem $>$ neuen $<\mathrm{Na}$ men Alina Khajtlina. Bezüglich der Topics unterscheiden sich beide Plattformen im Wesentlichen nicht voneinander, die ersten vier Topics Meinungsäußerung, Metaphysik, Menschen sowie Natur sind in beiden Fällen ident. Mit dieser Topicverteilung sind beide Profile eindeutig dem alläglichen Teilkorpus zuzurechnen, wie Abbildung 24 auf Seite 263 zeigt. Diese Einordnung lässt vermuten, dass in den sozialen Netzwerken (auto-)biographische Einträge, (Selbst-)Vermarktung und Meinungsäußerungen dominieren, während literarische Texte gegenüber den ŽŽ-Blogs ins Hintertreffen geraten. Nachfolgend werden Kudrjaševas Profile auf Facebook und Vkontakte miteinander verglichen und zu den Blogs in Beziehung gesetzt.

In beiden sozialen Netzwerken findet sich das Topic Meinungsäußerung auf Platz eins. Kudrjaševas Studium in St. Petersburg spielt auf Vkontakte eine gewichtige Rolle, so bewirbt die Autorin in einem Eintrag die Folkloredatenbank ihrer Universität (Kudrjaševa 2014e). Das später eingerichtete Facebook-Profil hingegen nimmt eher auf Kudrjaševas Tätigkeit für ein Kulturzentrum in München Bezug (Kudrjaševa 2014d). In beiden Fällen teilt die Autorin Werbung für verschiedene Veranstaltungen. Hinzu kommen politische Meinungsäußerungen, die in ihren Blogs 〈izubr〉 und 〈xelbot〉 kaum auftreten. Während Kudrjaševa etwa in Vkontakte die Festnahme von befreundeten studentischen Aktivistinnen und Aktivisten schildert (Kudrjaševa 2012d), taucht auf Facebook der Ukrainekonflikt auf: In einem umfangreichen Eintrag reflektiert Kudrjaševa die Radikalisierung der Menschen auf beiden Seiten (Kudrjaševa 2014g).

Auf Platz zwei folgt das Topic Metaphysik, das in beiden sozialen Netzwerken aus einer bunten Mischung an Texten besteht. So hat der Teufel Kudrjaševas Brille versteckt (Kudrjaševa 2012f) und sie berichtet von den >Freuden ^ des Prokrastinierens (Kudrjaševa 2014b). Beim Topic Menschen auf Platz drei kommt es zu kleinen Unterschieden zwischen den Plattformen. Vkontakte versammelt (auto-)biographische Miniaturen wie die folgende, veröffentlicht am Valentinstag 2012:

Короче, я купила шоколадку, как вы говорили, а он не пришел. В следующий раз не буду покупать. У меня челюсть отмерзла. Кстате [sic!], в этом городе дохрена мужиков 
в кепках и пуховиках. Будьте оригинальней при выборе гардероба, тем более, что зимняя кепка никого не красит. ${ }^{14}$ (Kudrjaševa 2012c)

Dieser kurze Text erinnert an die Meisterin der kleinen Form im Netz: Linor Goralik. Das einleitende Wort »короче« [»kurzum«] ist eine unverhohlene Anspielung auf Goraliks gleichnamigen Kurzgeschichtenband. Gleichzeitig reiht sich das angeblich Erlebte in die vielen gescheiterten Beziehungen aus dem Blog 〈izubr〉 ein. Vergleichbare Prosaminiaturen finden sich auf Facebook, beispielsweise über einen Mitreisenden im Bus (Kudrjaševa 2013b). Daneben tauchen aber immer wieder Gedichte auf, die Kudrjaševa gleichzeitig auch in ihrem lyrischen Blog veröffentlicht, nicht aber auf Vkontakte (Kudrjaševa 2015c, Kudrjaševa 2015e, Kudrjaševa 2015b). Der hier skizzierte Unterschied zwischen Vkontakte und Facebook lässt sich auch beim viertplatzierten Topic Natur beobachten. Auf Vkontakte sind es kurze Texte bzw. einzelne Gedanken, die mit ihren überraschenden Wendungen an Goralik erinnern: »Море всегда устроено так: вокзал-пляж-море. А здесь все наоборот: море-пляж-вокзал. Значит, я поеду домой по железной дороге.(c)« [»Das Meer ist immer so aufgebaut: Bahnhof-Strand-Meer. Aber hier ist alles umgekehrt: MeerStrand-Bahnhof. Das heißt, ich fahre nach Hause mit der Eisenbahn.(c)«] (Kudrjaševa 2012e).

Solche Kurztexte bleiben auf Vkontakte beschränkt, während Kudrjaševa auf $F a$ cebook auch im Topic Natur Gedichte veröffentlicht. Dabei markiert sie diese in gewissem Sinne als Fremdkörper, es finden sich Hinweise wie »осторожно стехи « [»Vorsicht Gädichte«] (Kudrjaševa 2015d) oder »cтехи, извините« [»Gädichte, entschuldigt «] (Kudrjaševa 2012l). Diese Warnhinweise deuten an, dass die Autorin Facebook nicht unbedingt als typisches Medium für Gedichte ansieht, sie lyrische Texte also gesondert kennzeichnen muss.

Die nun folgenden Topics und die entsprechenden Einträge sind in der Regel (auto-)biographischen Praktiken zuzurechnen. Zwischen den beiden Plattformen kommt es zu einzelnen Verschiebungen. So liegt das Topic Zeitangaben/Flüge in Vkontakte auf Platz sechs, während es auf Facebook erst auf dem achten Platz aufscheint. In beiden Fällen sind die Einträge (auto-)biographisch, Besuche in verschiedenen Städten werden beschrieben oder angekündigt (Kudrjaševa 2013c). Etwas präsenter ist das Topic Internet in Vkontakte mit 5\% gegenüber 4\% auf Facebook. In

$14 \mid$ »Kurzum, ich hab Schokolade gekauft, wie ihr gesagt habt, aber er ist nicht gekommen. Nächstes Mal kaufe ich nichts. Mir ist der Kiefer eingefroren. Übrigens, in dieser Stadt gibt es verteufelt viele Männer in Kappe und Daunenjacke. Seid origineller bei Eurer Auswahl der Garderobe, vor allem auch deshalb, weil eine Winterkappe niemanden schöner macht.« 
beiden Fällen handelt es sich um Meta-Einträge über das Internet, beispielsweise befürchtet Kudrjaševa, ihr Account auf Vkontakte wäre gehackt worden (Kudrjaševa 2012g). Das siebtplatzierte Topic Stadt kommt auf Vkontakte und Facebook fast gleich häufig vor. Ähnlich dem Topic Zeitangaben/Flüge werden vorwiegend Städtetrips angekündigt oder beschrieben (Kudrjaševa 2011e). Das Topic Literarische Texte (Vkontakte: Platz acht) ist auf Facebook häufiger: Platz fünf. Auf beiden Plattformen landen in diesem Topic einige Gedichte, sowohl von Kudrjaševa selbst wie auch von anderen. $\mathrm{Zu}$ letzterer Gruppe zählt Iosif Brodskijs »Sonetik « [»Sonettchen«] von 1964 (Kudrjaševa 2012j) ebenso wie ein Liedtext von Aleksandr Galič: »Ballada o večnom ogne« [»Ballade vom ewigen Feuer«] (1968) (Kudrjaševa 2014f).

Bei den jeweils letzten beiden Topics gibt es keine Entsprechungen mehr. Während in Vkontakte die Topics Geld (Platz neun) und Namen (Platz zehn) die häufigsten zehn Topics beschließen, sind es auf Facebook Politik (Platz neun) und Alltag (Platz zehn). Der Unterschied zwischen den beiden Plattformen könnte dem Faktor Zeit geschuldet sein, so beziehen sich Einträge im Topic Alltag auf Kudrjaševas Leben in München. Beispielsweise schreibt sie über Stereotype ihres Münchner Lebens (Kudrjaševa 2014c). Abgesehen davon ist Kudrjaševas Facebook-Auftritt >politischer als das Pendant auf Vkontakte. Dies zeigte sich bereits in den Einträgen des erstplatzierten Topics Meinungsäußerungen: In Vkontakte wird das Leben in Petersburg und insbesondere das Studium an der dortigen Europäischen Universität geschildert, während Facebook um Kudrjaševas späteres Leben in München kreist. Ein weiterer Unterschied ergibt sich hinsichtlich der eingesetzten Genres: In Vkontakte versucht sich Kudrjaševa an Kürzest-Texten à la Goralik, während sie auf Facebook formal unspektakuläre Einträge veröffentlicht. Einzige Ausnahme sind die Gedichte, die hier parallel zum ŽŽ online gestellt werden.

\section{INTERAKTIONSLINIEN}

Kudrjaševa stellt sich ihrem Publikum auf allen Plattformen und tritt in einen aktiven Dialog mit ihren Leserinnen und Lesern ein. Am meisten Interaktion ist im lyrischen Blog 〈izubr〉 zu finden. So kann der bereits analysierte Slam-Text »I ty ideš' po gorodu, i za tebja letjat babočki « [»Und du gehst durch die Stadt, und hinter dir fliegen Schmetterlinge her «] bis zum 30. März 2017 auf 1060 Kommentare verweisen. Das Publikum lobt den Text mehrheitlich in den höchsten Tönen, so schreibt 〈Daria Zakharova $:$ »Столько лет этому стихотворению (десять!), а я его [sic!] до сих пор от него в трепете, как в первый раз « [»So alt ist dieses Gedicht (zehn!), aber bis heute bringt es mich zum Beben wie beim ersten Mal.«]. Wie bereits erwähnt, ist 
es dieser Text, der Kudrjaševa zu einiger Berühmtheit im Runet verhilft, die große Zahl der Kommentare überrascht deshalb nicht.

In der Regel erhält die Autorin in den Kommentaren positive Rückmeldungen zu ihren Texten, manchmal wird aber auch Kritik laut. Dies zeigt sich in einer Serie von drei Einträgen, die insgesamt 932 Antworten bekommen. Zunächst veröffentlicht Kudrjaševa einen alternativen Text zu einem Lied der Gruppe Splin (Kudrjaševa 2007g), dessen 211 Antworten nicht nur positiv sind; so wird etwa die Betonung des Wortes > ракушка< [>Muschel<] diskutiert. Genervt von den Kommentaren schreibt sie sich am folgenden Tag den Frust von der Seele: »Что-то мне надоело. Такую погоду показывают, а я [...] сижу и порчу настроение чтением комментов.« [»Irgendwie reicht's mir. Wir haben so schönes Wetter, und ich (...) sitze hier und verderbe mir die Laune durch das Lesen von Kommentaren«] (Kudrjaševa 2007h). Schließlich stellt sie in den Raum, ihren Blog zu schließen oder gar zu löschen; die 306 Kommentare versuchen sie mehrheitlich davon abzubringen. Nachdem die Wogen geglättet sind, folgt ein Eintrag anlässlich ihres zwanzigsten Geburtstags mit 415 Glückwunsch-Kommentaren (Kudrjaševa 2007i). Kudrjaševa holt sich über die Kommentare also vorwiegend positives Feedback, abweichende Meinungen werden nicht gelöscht, gelten implizit aber als unerwünscht.

Interessant ist das Gedicht »pro angelov« [»über engel«], weil es als eines der wenigen Gedichte von Kudrjaševa einen politischen Hintergrund hat. Wie in Kapitel »Webauftritte mit Schwerpunkt Literatur « vermutet, wird es vom »topic modeling « nicht als politischer Text eingestuft, weil die Wortoberfläche $\mathrm{zu}>$ unpolitisch $<$ ist: »Восьмого мая они просыпаются среди ночи. / Старший из них говорит: >Черемуха зацветает< / Средний из них говорит: > Чепуху ты мелешь.< [...]« [»Am achten Mai werden sie mitten in der Nacht wach. / Der Älteste von ihnen sagt: >Die Kirschen blühen< / Der Mittlere von ihnen sagt: >Das ist Blödsinn.«《] (Kudrjaševa 2008e). Dieses Gedicht liegt mit 264 Antworten auf Platz fünf der meistkommentierten Einträge im Blog 〈izubr〉. Politische Inhalte in lyrischer Verpackung können im literarischen Teilkorpus durchaus Aufmerksamkeit erlangen, die dabei entstehende Diskussion bleibt aber gesittet und widmet sich verschiedenen Vorstellungen von $>$ Heimat<.

Manchmal erinnern die Kommentare an die Diskussion nach einer Lesung. So fragt 〈glornaith〉: »Изюбрь, откуда Вы такие стихи берете?..« [»Hirsch, woher nehmen Sie solche Gedichte?«], worauf 〈izubr〉 antwortet: » Мы просмотрели Ваш проект и решили закупить партию травы, которую Вы курите.<(с) ;)《 [»>Wir haben uns Ihr Projekt angesehen und entschieden, einen Teil des Grases zu kaufen, das Sie rauchen $<(c) ;$;) $($ Gercen 2006). Solche Diskussionen bieten Kudrjaševa in ihrer Paratextualität einen wichtigen Raum zur (Selbst-)Inszenierung, denn in den 
Gedichten selbst vermutet das Publikum in der Regel keine (auto-)biographischen Details im Hintergrund. Das Gedicht »pis'mo sčast'ja « [»glücksbrief «] etwa bezieht ein Großteil der Leserinnen und Leser auf sich selbst. So schreibt 〈miya_miya〉: »каждая строчка - будто мной прочувствована « [»als ob ich jede Strophe gefühlt hätte«], und 〈bunchik〉 meint: »Аж страшно насколько это про меня... « [»Unheimlich, wie sehr es da um mich geht...«]. Die Allgemeingültigkeit des Gedichts betont $\langle$ fessen〉: »про себя, как про всех и про каждого...« [»Es geht um mich ebenso wie um alle und um jeden...«] (Kudrjaševa 2007j).

Explizit auf Kudrjaševa bezogen wird das Gedicht hingegen selten, so merkt 〈klukwa〉 an: »замечательно... как будто изнутри вырвалось.« [»wunderbar.. als ob es aus dem Innern herausbrechen würde«]. Dabei erteilt der Konjunktiv einer biographistischen Lesart des Gedichts eine implizite Absage. Schließlich fragt 〈tanyka〉 nach: »эт пра каво?« [»Um wen geht's?«], woraufhin 〈izubr〉 (und nicht Kudrjaševa) antwortet: »Пра миня.« [»Um mich.«]. Darauf reagiert 〈tanyka〉 wie folgt: »a йа думала, пра миня « [»Und ich hab geglaubt, um mich«] (〈tanyka〉 2007). Die Verwendung des russischen Internetslangs, des auf Seite 74 vorgestellten Olbanischen, deutet an, dass das Gespräch nicht ganz ernst gemeint ist. Entsprechend vorsichtig muss die Aussage von 〈izubr〉 verstanden werden, vor allem, weil 〈tanyka〉 das Gedicht schlussendlich auch auf sich selbst bezieht - wie der Großteil des Publikums.

Manchmal stellt Kudrjaševa in den Kommentaren selbst einen (auto-)biographischen Hintergrund ihrer Gedichte in den Raum. So beschreibt das lyrische Subjekt in den letzten beiden Strophen des bereits erwähnten Gedichts »Devočka, živuščaja v seti...« [»Das Mädchen, das im Netz lebt...«] die schwierige Trennung von einer Partnerin oder einem Partner. Auf diese Strophen bezogen schreibt Kudrjaševa in den Kommentaren: »Дело в том, что не очень хочется, чтоб проходило. Хочется, чтоб вернулось как раньше. :(« [»Es geht darum, dass ich nicht will, dass es vorbeigeht. Ich will, dass es so wird wie früher :(«] (Kudrjaševa 2004c). Im ebenfalls bereits analysierten Gedicht »(izlišnaja didaktika) dočeri« [»(überflüssige didaktik) für die tochter «] bietet der Appell an die Tochter dem lyrischen Subjekt eine Gelegenheit, über sich selbst nachzudenken. Dazu bemerkt Kudrjaševa in einem Kommentar: »Текст обращен к гипотетическому человеку а скорее к себе« [»Der Text richtet sich an eine hypothetische Person, vor allem aber an mich«]. Wieder ist es der Paratext, der eine (auto-)biographische Lesart suggeriert, verstärkt noch durch die Tatsache, dass das lyrische Subjekt des Gedichts in diesem Fall weiblich ist. Auch die bereits erwähnten intertextuellen Verweise auf das Studien-Gedicht wirken auf kundige Leserinnen und Leser in ähnlicher Weise, schließlich kommen dort einige (auto-)biographische Splitter vor. 
Beispiele eines gemeinsamen Schaffensprozesses lassen sich ebenso finden, etwa in den Kommentaren zum Slam-Text »Ot moich dekabrej do tvoej vesny...« [»Von meinen Dezembern zu deinem Frühling...«]. Besonders hervorgehoben wird vom Publikum die Musikalität dieses Textes, so bemerkt Igor' Belyj (2005) alias 〈bujhm〉: »это песенка :)《 [»Das ist ein Liedchen :)《] und steuert eine Melodie bei, über die in weiterer Folge lange diskutiert wird. Kudrjaševa inspiriert ihr Publikum zu Kreativität; andererseits legt sie offen, woher sie ihre eigene Inspiration bezieht: »Линор Горалик - это наше всё, да.« [»Linor Goralik ist unser Ein und Alles, ja.«] (Kudrjaševa 2008d).

Der Blog 〈xelbot $\rangle$ zeichnet sich durch eine (auto-)biographischere Ausrichtung aus als $\langle$ izubr $\rangle$; trotzdem finden sich noch einige Gedichte. Dieser inhaltliche Spagat lässt sich auch anhand der beiden meistkommentierten Einträge feststellen. An der Spitze liegt ein Text mit 345 Kommentaren. Kudrjaševa schlägt darin ein literarisches Spiel vor, das der im Runet weitverbreiteten Regelpoetik folgt. Das Publikum soll Verse nach folgendem Muster erstellen: »Бывает просыпаешься с утра ты / C неясным ощущением утраты « [»Manchmal wachst du auf am Morgen / Mit einem unklaren Gefühl, voller Sorgen«] (Kudrjaševa 2012a). In den Kommentaren beteiligen sich die Leserinnen und Leser an diesem Spiel. Auf Platz zwei landet ein Eintrag mit 251 Antworten. Darin macht Kudrjaševa ihre Entscheidung publik, nach München zu übersiedeln (Kudrjaševa 2012k). Auch in diese >private< Konversation spielt die Literatur hinein, so kommentiert 〈gabblgob〉: »надеюсь, твои стихи станут ещё чище и пронзительнее« [»ich hoffe, deine gedichte werden noch reiner und erschütternder «]. Tendenziell weniger Reaktionen erhält Kudrjaševa auf ihre Einträge in sozialen Netzwerken. Ein soziologisches Experiment kommentieren auf Facebook 86 Leute (Kudrjaševa 2014a), einen politischen Eintrag 84 (Kudrjaševa 2014g). Auf Vkontakte sind generell keine Kommentare ersichtlich, wohl aber Zahlen für >Likes< und >Shares<; ein Gedicht kommt immerhin auf 121 >Likes< (Kudrjaševa 2013a).

\section{RESÜMEE}

Ein Vergleich der verschiedenen Plattformen zeigt, dass Kudrjaševa in ihrer (Selbst-) Inszenierung keinen klaren Regeln folgt. Obwohl sie beispielsweise den Blog 〈izubr〉 als explizit lyrisch konzipiert, während der Blog 〈xelbot〉 als Tagebuch gedacht ist, finden sich in beiden Blogs sowohl Gedichte als auch (auto-)biographische Texte; auch in den sozialen Netzwerken Vkontakte und Facebook tauchen immer wieder Gedichte auf. Kudrjaševas Auftritte auf den unterschiedlichen Plattformen weisen 
durchaus Eigenheiten auf: Experimente mit Kürzest-Texten in Vkontakte, politische Meinungsäußerungen auf Facebook, Slam-Texte im lyrischen Blog. Allerdings konstruiert Kudrjaševa nicht für jede Plattform ein neues Selbst. Die Rolle des Hirsches 〈izubr〉 im lyrischen Blog nimmt sie beispielsweise nicht so an, wie das Goralik mit ihren Hasen macht. Sowohl Dichte als auch Konkretheit an (auto-)biographischer Information nehmen stetig zu; ausgehend von den relativ unbestimmten lyrischen Subjekten des Blogs 〈izubr〉 über den Blog 〈xelbot〉 hin zu den beiden Profilen in sozialen Netzwerken, die fest im Alltagskorpus verankert sind. Dabei spielt auch eine zeitliche Komponente eine Rolle: Dominieren zunächst lyrische Texte, kommen nach und nach immer mehr (auto-)biographische Texte hinzu, die Online-Auftritte >wandern $<$ vom literarischen in das Alltagskorpus.

Die Unbestimmtheit des lyrischen Blogs wird durch die stärker (auto-)biographischen Blogs >überschrieben`. Gewisse Themenkreise sind über sämtliche OnlineAuftritte von Kudrjaševa konstant: Studium in Petersburg, Liebe zur deutschen Sprache, Umzug nach München. Diese Kongruenz befördert eine (auto-)biographische Lesart von Kudrjaševas Lyrik. Verstärkt wird dies durch Paratexte wie Titel, Nachsätze, Kommentare, in denen entweder Kudrjaševa selbst oder aber das Publikum einen (auto-)biographischen Hintergrund der Texte imaginieren. Diese Paratexte sind in der Regel sehr kurz und können daher für sich genommen kein elaboriertes Bild der Autorin vermitteln. Allerdings sind diese kurzen Texte bei Kudrjaševa zueinander relativ kongruent; auf diese Weise kann die schattenhaft angedeutete, bruchstückhafte (Selbst-)Inszenierung von treuen Leserinnen und Leser auf- bzw. zusammengelesen werden und dadurch konkretere Formen annehmen.

Mit der Einrichtung ihres Blogs 〈xelbot〉 möchte Kudrjaševa ihre Person online etwas deutlicher auftreten lassen; die bruchstückhafte (Selbst-)Inszenierung über Paratexte scheint der Autorin nicht mehr zu genügen. Außerdem stehen einer (Selbst-) Inszenierung über paratextuelle Fragmente die zahlreichen Identifikationsangebote in den Gedichten im Weg, die dem Publikum nahelegen, sich selbst im lyrischen Subjekt zu imaginieren. Dies wird von den Leserinnen und Lesern geschätzt; sobald Kudrjaševa ihre persona stärker akzentuiert, rebelliert das Publikum. Wie bei Akunins Politisierung kommt die Änderung in der (Selbst-)Inszenierung nicht gut an. Fixe Vorstellungen in den Köpfen der Leserinnen und Leser - die imaginierte Performativität - erleichtern einerseits die (Selbst-)Darstellung, weil sie aus wenigen Andeutungen ein komplettes Bild formen. Die Korrektur oder Neuausrichtung dieses Bildes ist im Gegenzug offensichtlich nicht ohne Widerstand möglich. 